\title{
Discontinuous Precipitation and Dissolution in Cu-4.6 at\% In Alloy under the Effect of Plastic Deformation and the Temperature
}

\author{
Said Bensaada, Hamoudi Mazouz, Mohamed Tewfik Bouziane \\ Laboratory LARHYSS Université Mohamed Khider, Biskra, Algeria. \\ Email: s.bensaada@univ-biskra.dz \\ Received January $19^{\text {th }}, 2011$; revised March $17^{\text {th }}, 2011$; accepted May $9^{\text {th }}, 2011$.
}

\begin{abstract}
The study of the discontinuous precipitation reaction and the lamellar precipitate dissolution in the alloy Cu-In system provoked a considerable benefit and has been the subject of many theoretical and experimental investigations. The aim of this work is to make the evidence on the one hand the effect of the plastic deformation on the mechanism of the discontinuous precipitation reaction such as nucleation, growth and lamellar coarsening and in other hand the effect of temperature on the characteristics and front behavior movement of the opposite reaction (discontinuous dissolution). Different techniques of analysis have been used in this respect such as the optical microscopy, the differential thermal analysis and the microhardness Vickers. The obtained results confirm various works achieved in this field.
\end{abstract}

Keywords: Cu-In Alloy, Discontinuous Precipitation, Dissolution, Plastic Deformation, Temperature

\section{Introduction}

\subsection{Discontinuous Precipitation}

The precipitation phenomena take a considerable place in metal solutions, because it modifies the alloy properties, sometimes in favourable way leading to the rise of hardness and load breaking. The final state of the precipitation process is of several phases.

Generally the reaction of precipitation consists of the decomposition of a supersaturated solid solution $\alpha_{0}$ (mother phase) in a mixture of two phases of different compositions [1], according to the following reaction:

$$
\alpha_{0} \rightarrow \alpha+\delta
$$

where $\alpha$ is the girl phase, depleted in alloy element and has the same structure as $\alpha_{0}$ the mother phase and $\delta$ the precipitated phase rich in alloy element and can be:

- A mixed crystal with the same structure, the case of discontinuous precipitation in the alloy system $\mathrm{Au}-\mathrm{Ni}$ [2].

- A mixed crystal with a different structure, the case of the alloy system Pb-Sn [3].

- An intermetallic phase, the case of the alloy system $\mathrm{Cu}-\mathrm{Zn}[4]$.

- A liquid phase, the case of the alloy system Pb-Bi [5]. Discontinuous precipitation in the alloy $\mathrm{Cu}$-In system has been the subject of many research tasks [6-8] and the supersaturated solid solutions of this alloy system is decomposed in continuous and discontinuous modes, appearing at high and low temperature respectively. The favourable sites supporting the appearance of the cellular precipitate are the grain boundaries of large orientation $[9,10]$. The average size of the initial grains has also a considerable influence on the precipitate morphology.

The mechanisms of discontinuous precipitation nucleation suggested by Fournelle and Clark [11], then by You and Turnbull [9] are most plausible in this alloy system, i.e. it is a transformation related to the grain boundary dynamics. The growth model in this alloy system is that proposed by Frebel and Schenk [12] and of which the speed growth of the precipitated lamellas depends primarily on the speed of ageing annealing and the solute content of this alloy system, Figure 1 [13].

Two types of cellular reactions were observed by Spenger and Mack [14] in this alloy system, one fine and the other coarse, in both cases the lamellas are uniformly distributed. Predel and Gust [15] has shown also the same observation Figure 2, where the formation of the coarse lamella proceeds mainly between two fine lamellas and in both cases the process is controlled by the diffusion on the grain boundaries. The fine lamellas are uniform- 


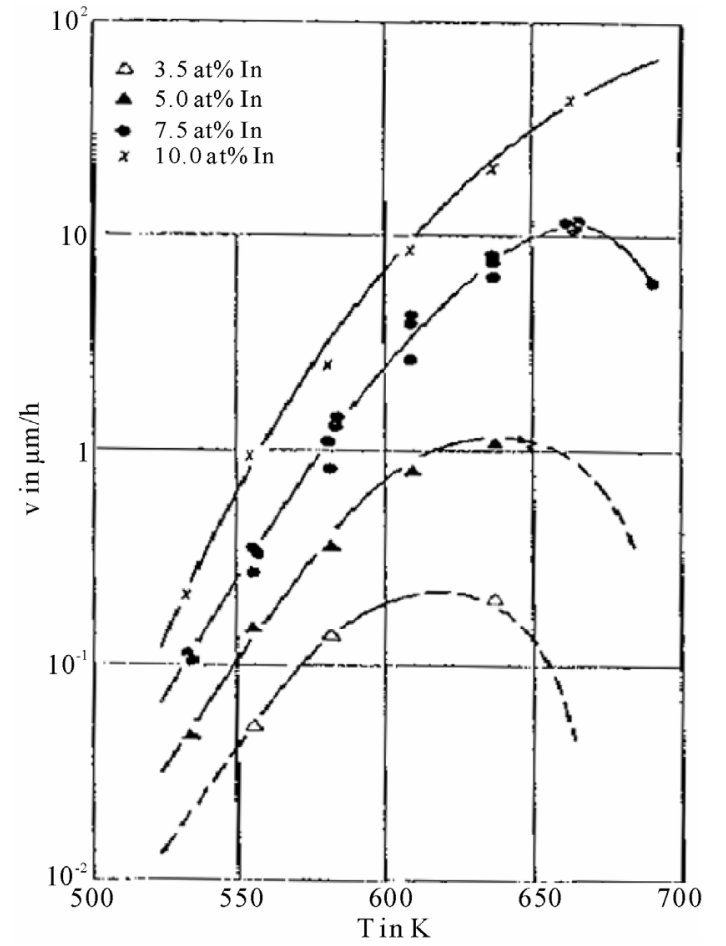

Figure 1. Growth speed of precipitate during annealing time in the Cu-In alloy system [13].

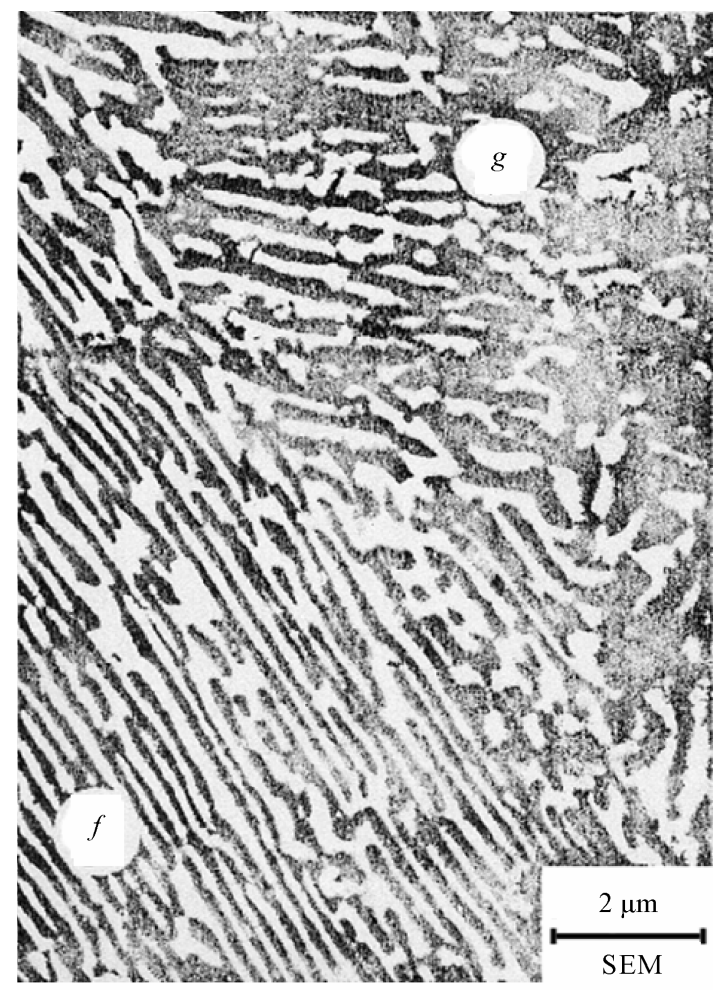

Figure 2. Morphology of lamellar precipitate in $\mathrm{Cu}-7,5$ at \% In alloy, homogenized, quenched and annealing during 3,5 $h$ at $392^{\circ} \mathrm{C}$ [15]. ly distributed; in contrast the distribution of thick lamellas is disordered, so there is a competition between the primary reaction of precipitation and the coalescence of the lamellas.

In old work one could not observe the coarse lamellas, because probably they appear only after long annealing time. This same phenomenon was observed in many alloys such as (Al-Ag [16], $\mathrm{Al}-\mathrm{Cu}$ [17], $\mathrm{Au}-\mathrm{Fe}$ [18], $\mathrm{Cu}-\mathrm{Ag}$ [19, 20], Fe-Zn [21], Fe-Ni-Ti [22], Ni-Sn [23], Pb-Na [24], Cu-Ga [25], Cu-In [26] and Zn-Al [27]. The types of precipitate in this alloy system have the shapes of hem [28], quadratic and fissure [29]. Experimentally, it was shown that a predeformation with the ageing annealing affects considerably the mechanism and the kinetics of precipitation [30]. D. B. Williams [31] affirmed that under the influence of the deformation, the speed of continuous precipitation increases consequently, the degree of supersaturation in solute atom decreases, which implies a reduction in the driving force of the cellular reaction.

\subsection{Discontinuous Dissolution}

The dissolution of the lamellate structure $\beta+\alpha$ (biphasic structure) formed after annealing is carried out according to the reaction: $\beta+\alpha \rightarrow \alpha$.

This can take place at any temperature higher from 20 to $50^{\circ} \mathrm{C}$ at the solvus temperature (critical temperature of solubility) corresponding to the alloy composition. Dissolution is easy and rapid if this critical temperature is raised, and supported by diffusion of the addition element in the matrix. The solid solution results after disappearance of the precipitate, has however a uniform composition only if the dissolution heat treatment were sufficiently prolonged (of about an hour) at a temperature higher than the solvus temperature, to ensure by diffusion a perfect homogenization (a complete dissolution).

The dissolution process is perhaps explained by Figures 3(a) and 3(b) represented on the one hand the discontinuous precipitation diagram on the grain boundary with $\alpha_{0}$ is the mother phase (single-phase structure), the $\beta$ precipitate in the lamellate form and the new phase $\alpha$, and in other hand by the dissolution of precipitate with grain boundary displacement (GB) according to the reaction front (RF) [32].

According to a study made on several alloy systems and among the Al-38 at \% Ag alloy based on the microhardness measure, the dissolved phase leads to the alloy hardening, it increases the lattice tension due to the precipitate rich in solute by the introduction of this last into the solid solution. In the same way, the fragmentation of the lamellate of the $\beta$ phase causes the same effect. The mechanical properties of the alloy during the discon- 


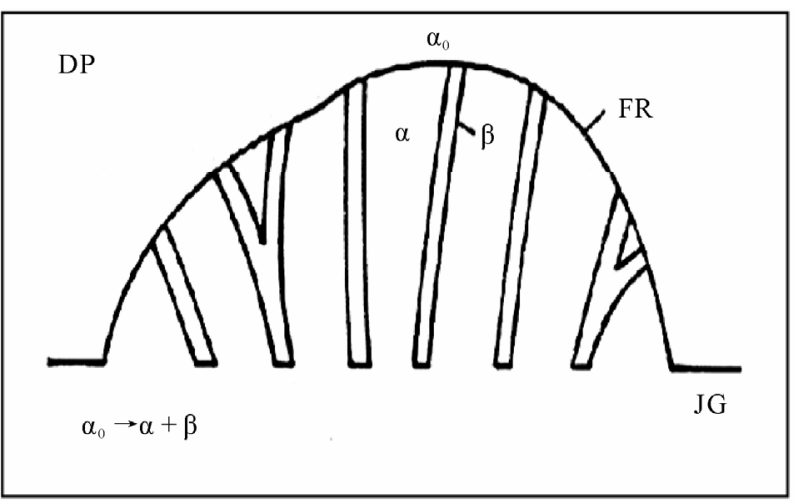

(a)

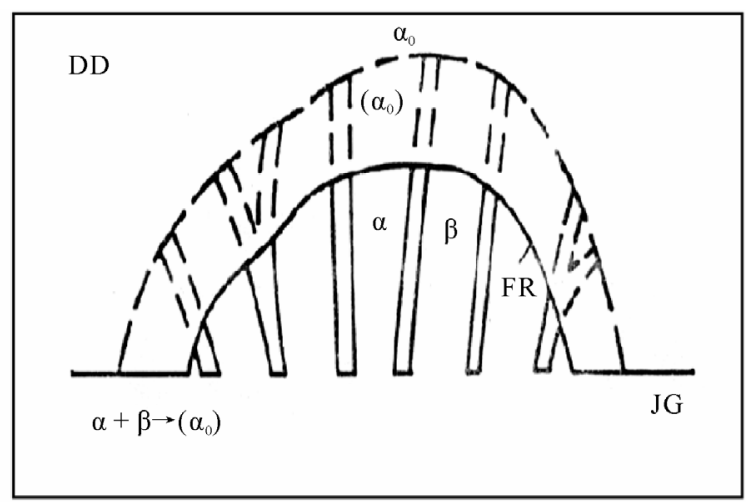

(b)

Figure 3. Schematic of discontinuous precipitation (a) and discontinuous dissolution (b) [32].

tinuous dissolution treatment depend on the alloy properties before dissolution.

S. P. Gupta [33] noticed that the dissolution of the lamellate precipitates in the same alloy is of a discontinueous type. I. G. Solorzano and W. Gust [34] have shown that an adequate heat treatment makes it possible to develop two different mechanisms of dissolution, one at $480^{\circ} \mathrm{C}$ leading to a discontinuous dissolution where the atoms diffusion is carried out through the reaction front and the other at $580^{\circ} \mathrm{C}$ leading after 60 seconds to a continues dissolution or the atoms diffusion is carried out in volume, the latter is accomplished by a recrystallization due to the presence of dislocations in the precipitated lamella, which supports the formation of new grains. The increase in the dislocations rate is due to the thermal cycle. Schapiro and Kirkaldy [35] have observed the existence of twins inside the precipitated lamella which supports the process of recrystallization. S. P. Gupta and B Prasard [36] found that the applied technique of the thermal cycle to a $\mathrm{Cu}-\mathrm{In}$ alloy causes a refinement of the grain.

\section{Experimental Methods}

The significant part of the equilibrium diagram of the alloy $\mathrm{Cu}$-In system is illustrated in Figure 4, which corresponds to the small percentage of Indium. The maximum solubility of the $\alpha$ phase is 18.1 at $\%$ In at $574^{\circ} \mathrm{C}$, the $\delta$ precipitated phase $\left(\mathrm{Cu}_{9} \mathrm{In}_{4}\right)$ from the supersaturated phase with a composition of 29 to 30.6 at \% In at all the temperatures below $613^{\circ} \mathrm{C}$ [37].

The alloy used for this investigation is the $\mathrm{Cu}-4.6$ at $\%$ In alloy obtained by vacuum induction melting under inert atmosphere (Argon) from Copper $(5 \mathrm{~N} 5 \mathrm{Cu})$ and Indium (5N5In) very pure. The samples investigated in the experimental study are homogenised for 27 days at $\mathrm{T}=$ $600^{\circ} \mathrm{C}$, quenched in water. For the effect of deformation on the discontinuous precipitation, we have used 3 sam- ples, where two samples are deformed by cold rolling, Table 1.

The ageing treatments were carried out at $400^{\circ} \mathrm{C}$ to cause only the discontinuous precipitation. For dissolution, three different temperatures of $460^{\circ} \mathrm{C}, 500^{\circ} \mathrm{C}$ and $600^{\circ} \mathrm{C}$ are used and on the same aged samples, see Table 2.

The structural evolution is of microhardness Vickers $\left(\mathrm{HV}_{0,1}\right)$. The structural morphology is followed by various techniques such as optical microscopy, the differenttial thermal analysis and the microhardness Vickers.

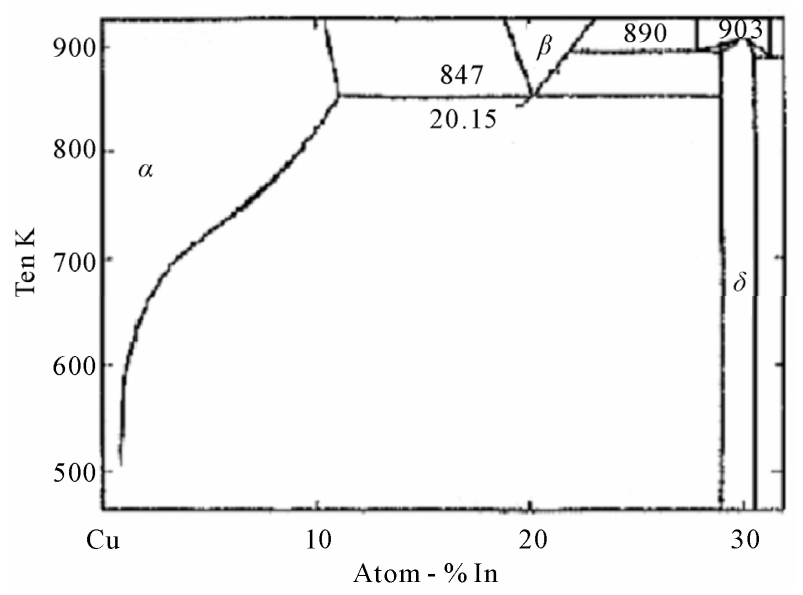

Figure 4. Part of equilibrium diagram of Cu-In alloy system [37].

Table 1. The samples used in the precipitation study.

\begin{tabular}{ccc}
\hline samples & state & $\mathrm{HV}_{0,1}$ \\
\hline 1 & quenched & 45 \\
2 & deformed, $\varepsilon_{2}=20 \%$ & 52 \\
3 & deformed, $\varepsilon_{2}=70 \%$ & 71 \\
\hline
\end{tabular}



and the Temperature

Table 2. The samples used in the dissolution study.

\begin{tabular}{lcccc}
\hline \multicolumn{1}{c}{ samples } & $\mathrm{HV}_{0.1}$ & Aged at $\mathrm{T}=400^{\circ} \mathrm{C}$ & $\mathrm{HV}_{0.1}$ after ageing & $\mathrm{T}^{\circ} \mathrm{C}$ of dissolution \\
\hline 1. not deformed & 42 & for 97 hours & 72 & 600 \\
2. deformed $\varepsilon=20 \%$ & 48 & for 67 hours & 92 & 500 \\
3. deformed $\varepsilon=70 \%$ & 67 & for 53 hours & 104 & 460 \\
\hline
\end{tabular}
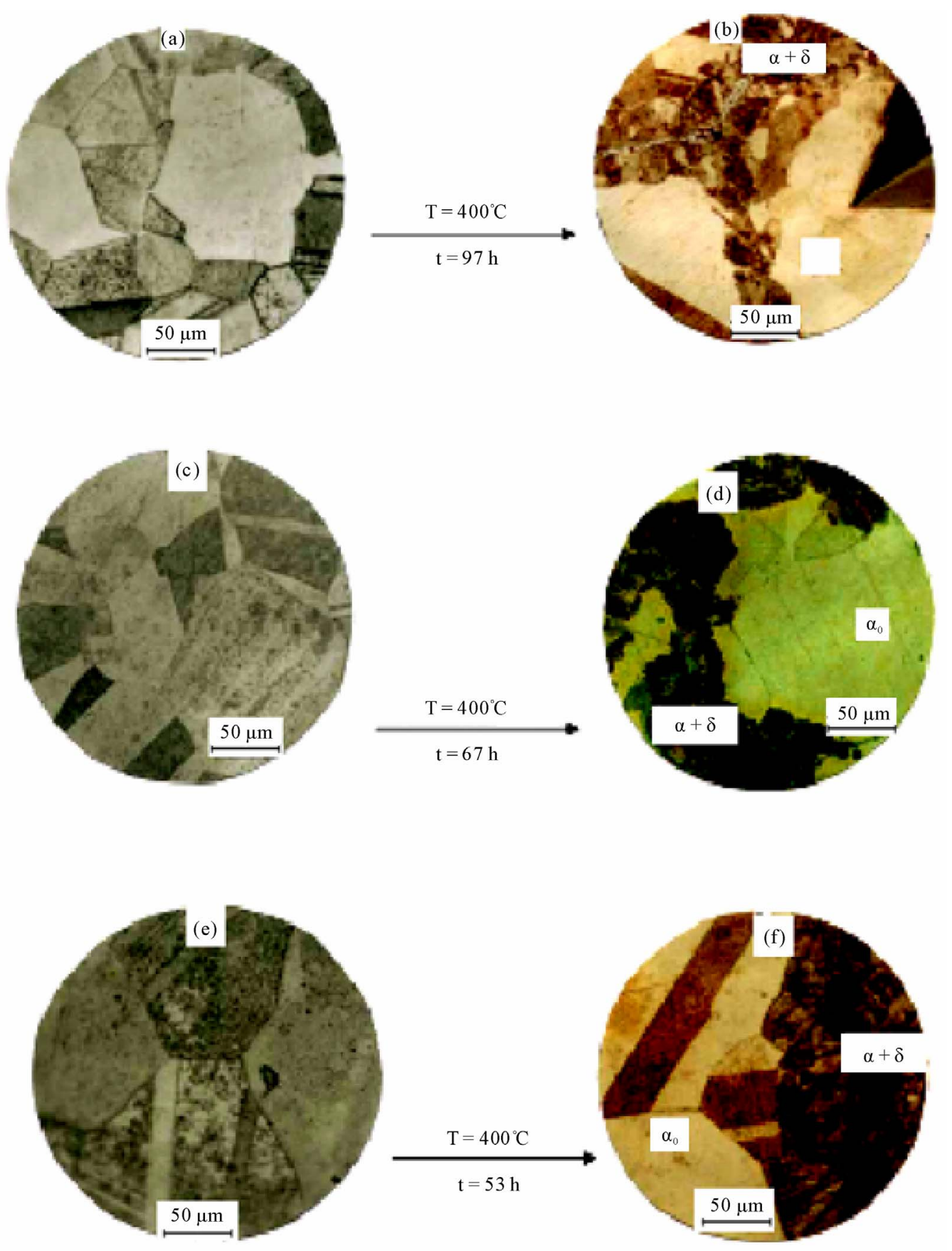

Figure 5. Structural evolution of $\mathrm{Cu}-4.6$ at \% In alloy, after homogenization during 27 days at $600^{\circ} \mathrm{C}$, quenched in water (a), deformed of $20 \%$ (c) and of $70 \%$ (e) and annealing at $400^{\circ} \mathrm{C}$ during $97 \mathrm{~h} \mathrm{(b),} \mathrm{67h} \mathrm{(d)} \mathrm{and} \mathrm{53h} \mathrm{(f).}$ 


\section{Results and Discussion}

\subsection{Discontinuous Precipitation}

The temperature of ageing of $400^{\circ} \mathrm{C}$ reveals only the discontinuous precipitation (lamellate) and not of other morphology precipitates whatever the deformation rate, the precipitate are of the double hems type, Figures 5(b), 5(d) and 5(f) with the reaction front has a corrugated pace. The mechanism of folding noticed by the authors $[9,11]$ was observed, i.e. in the early times of nucleation, the grain would be folded locally to absorb the precipitates, Figure 6, which confirms a precipitation with the grain boundary dynamics.

However precipitation is much slower on a grain boundary of small size than on a grain boundary of large size, an average critical size of grains boundaries is deserved to be in evidence for such cases.

The deformation does not have any effect on the precipitates growth, but however we have observed two cellular reactions, one of fine lamellas and the other coalesced, Figure 6, which implies a competition between the primary reaction of precipitation and the coalescence of the lamellas. The formation of the coalesced lamellas is carried out mainly between two very close fine lamellas; this enlargement probably starts when the totality or less most of the structure is precipitated. For the coalesced lamellas it is always about the same phase as that of discontinuous precipitation. The lamellas preserve

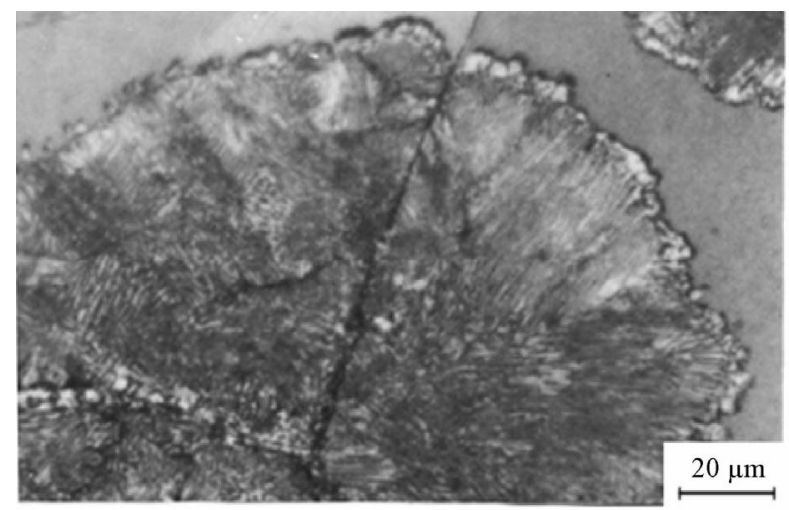

Figure 6. Structural evolution of $\mathrm{Cu}-4.6$ at\% In alloy, after homogenization during 27 days at $600^{\circ} \mathrm{C}$, quenched in water, deformed of $20 \%$ and annealing at $400^{\circ} \mathrm{C}$ during $67 \mathrm{~h}$.

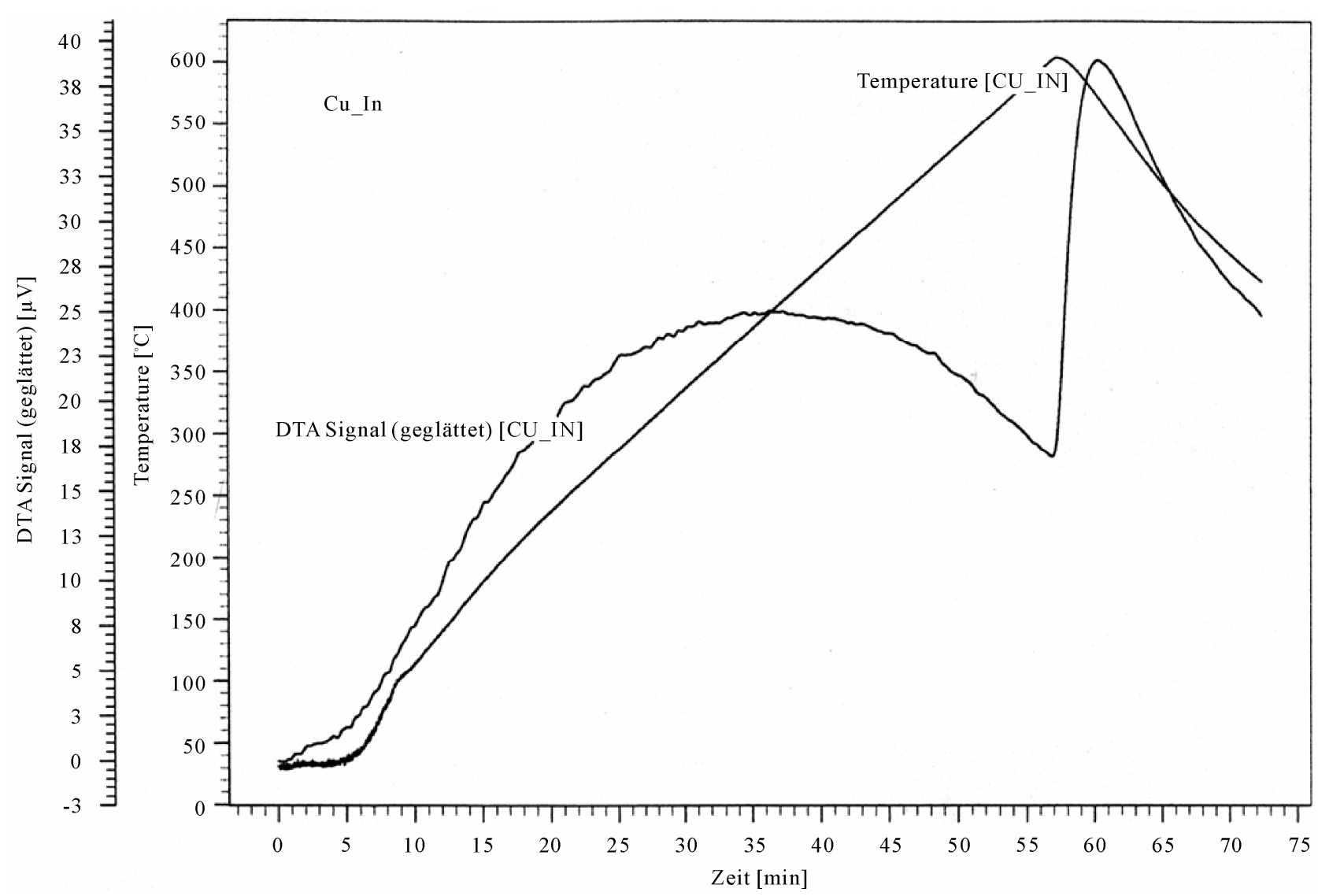

Figure 7. D.T.A curves of $\mathrm{Cu}-4.6$ at $\%$ in alloy, after homogenization during 27 days at $600^{\circ} \mathrm{C}$, quenched in water, of sample 1 not deformed. 
their morphology anisotropy during their growth; the growth of the lamellas is observed in the deformed than in the not deformed samples, it is a growth in width leading to narrow hems. The differential thermal analysis, Figure 7 which the curve is characterized by a variation of energy during the rise in the temperature and the exothermic peak confirms the precipitation of a new phase which corresponds to the intermetallic phase $\mathrm{Cu}_{9} \mathrm{In}_{4}$. The evolution of the microhardeness, Figure 8 clearly shows the structural hardening of all the samples during discontinuous precipitation; however this hardening is relatively significant with the rise in the work hardening rate.

\subsection{Discontinuous Dissolution}

The various temperatures used during dissolution of precipitates lamellate have developed in two different mechanisms of dissolution. The temperatures of $600^{\circ} \mathrm{C}$ and $500^{\circ} \mathrm{C}$ led on the one hand to a dissolution of continues type where the atoms diffusion is carried out in volume (Figures 9(b) and 9(d)) and on the other hand supported the formation of twins after dissolution of precipitates.

On the other hand the temperature of $460^{\circ} \mathrm{C}$ has shown a discontinuous dissolution of discontinuous type, Figure 9(f), with opposite migration of the reaction front (RF) and where the atoms diffusion is carried out mainly through the grain boundary. However the effect of the temperature on the speed of dissolution is observed, because in comparison with the last two temperatures $\left(600^{\circ} \mathrm{C}\right.$ and $\left.500^{\circ} \mathrm{C}\right)$, the process of dissolution in the case of the temperature of $460^{\circ} \mathrm{C}$ is relatively slow. The dissolution of precipitates in the three cases has lead to a fall of the microhardness, Figure 10.

\section{Conclusions}

The results obtained by different technique of analysis used in this respect are coherent between them and confirm several work devote to the study of the reaction of precipitation and discontinuous dissolution in the alloy $\mathrm{Cu}$-In system. However the temperature of $400^{\circ} \mathrm{C}$ supports only discontinuous precipitation and not other precipitates morphology was observed. The lamellas are of double hems type with a corrugated pace. The presence of the fine lamellas and coalescences confirms the existence of the competition between precipitation and the coalescence of the lamellas. The grain boundary is characterized by a crumpling to absorb the precipitate during their movement. The effect of the deformation rate is observed on the precipitation speed during the initial stage; on the other hand no effect was observed on the coalescence of the precipitate. Precipitation is carried out mainly in the coarse grains zones, because the initial average size of the grains has an influence on the mecha-

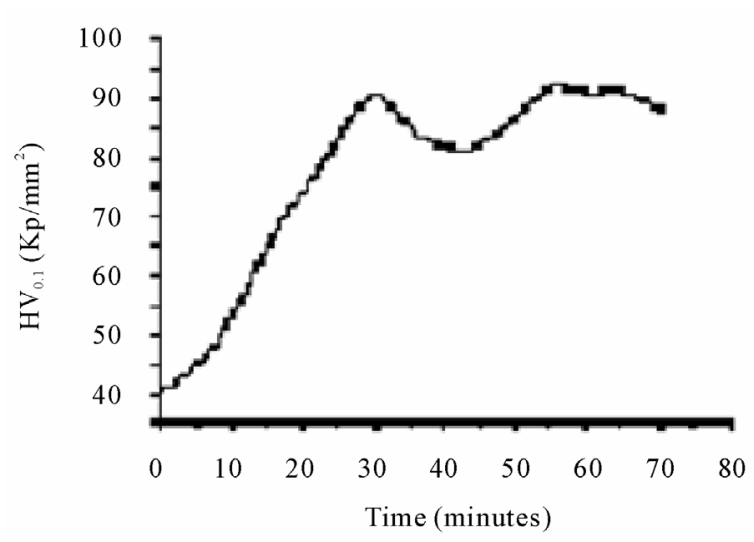

(a)

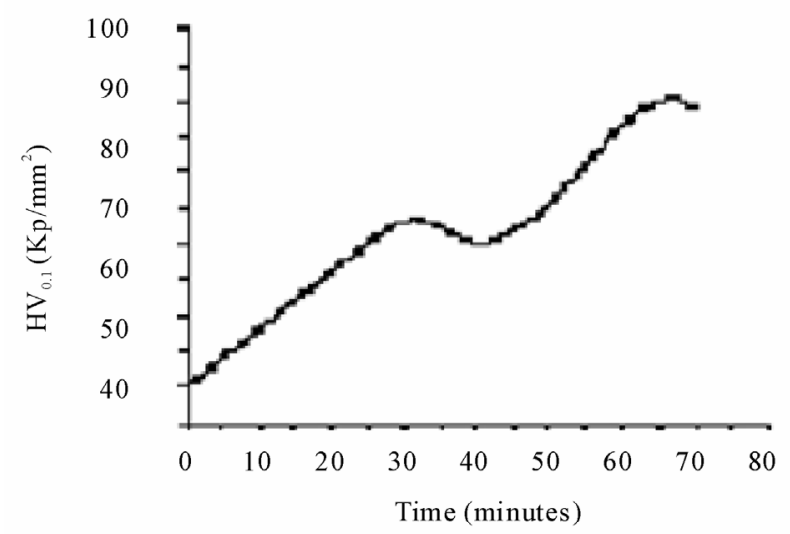

(b)

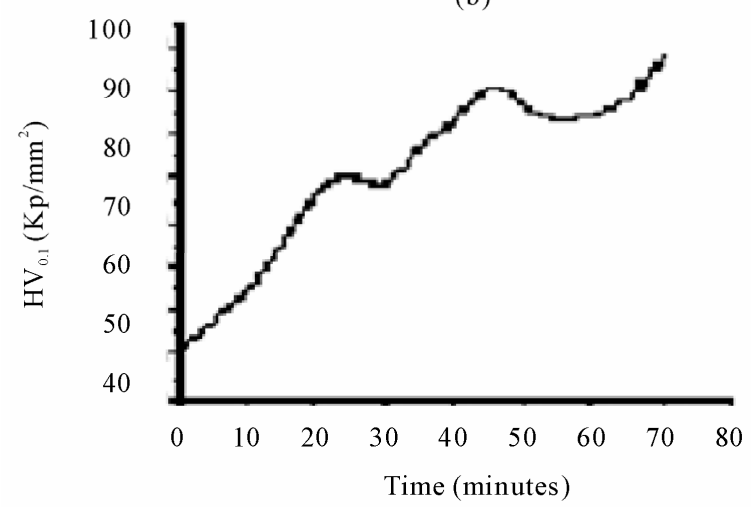

(c)

Figure 8. Hardness evolution $\mathrm{HV}_{0,1}$ during annealing time Cu-4.6 at\% In alloy, after homogenization during 27 days at $600{ }^{\circ} \mathrm{C}$, quenched in water (a), deformed of $20 \%$ (c) and of $70 \%$ (e) and annealing at $400^{\circ} \mathrm{C}$ during.

nisms of precipitation. The appearance of the new intermetallic phase $\mathrm{Cu}_{9} \mathrm{In}_{4}$ led to the hardening of alloy. The effect of the temperature on the mechanism of the dissolution of the lamellate precipitate has shown on the one hand that dissolution is carried out into two different 

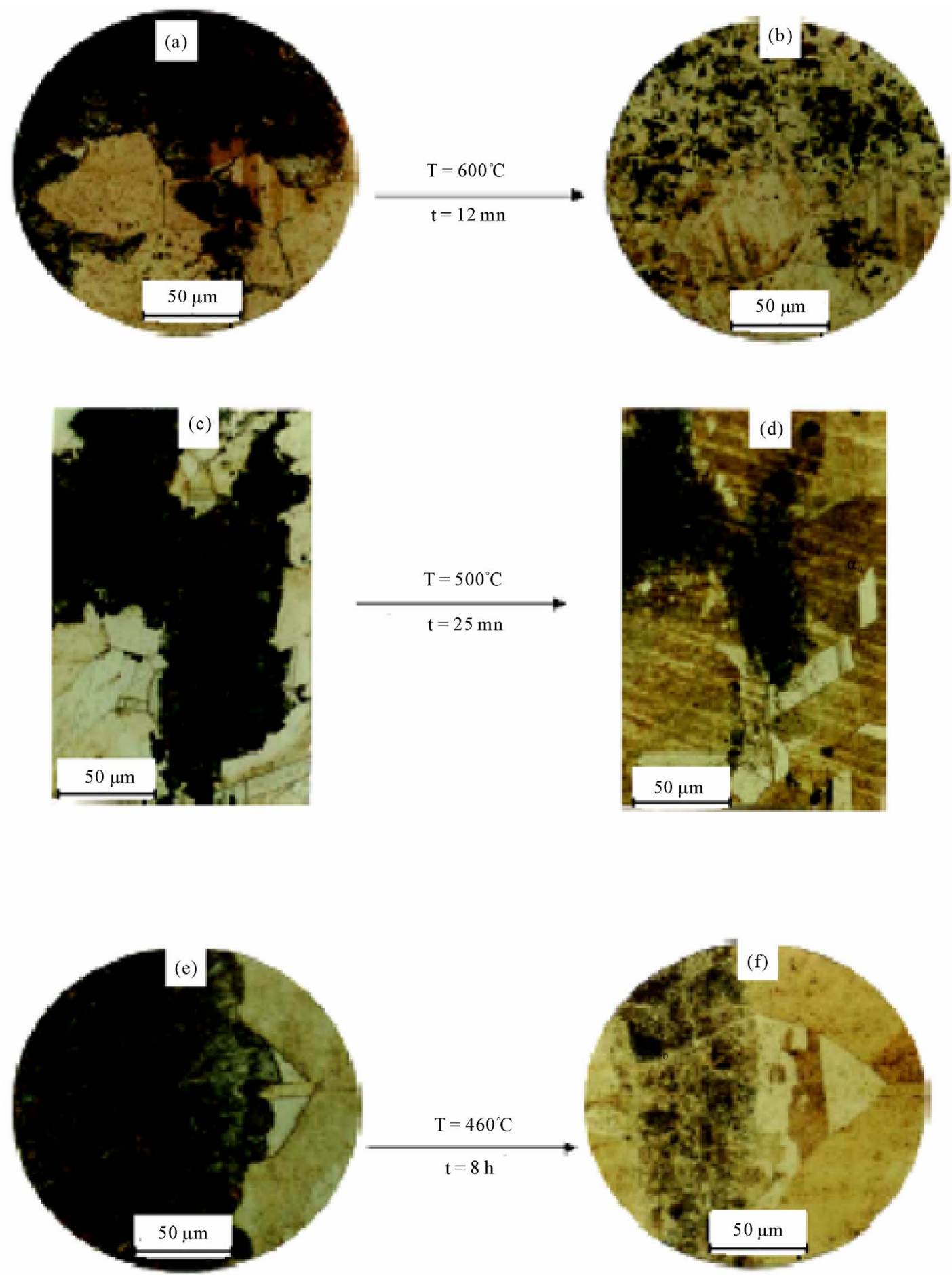

Figure 9.Structural evolution of $\mathrm{Cu}-4.6$ at \% In alloy, after homogenization during 27 days at $600^{\circ} \mathrm{C}$, quenched in water, annealing at $400^{\circ} \mathrm{C}$ during $97 \mathrm{~h}$ (a), $67 \mathrm{~h}$ (c) and $53 \mathrm{~h}$ (e) and dissolution at $600^{\circ} \mathrm{C}$ during $12 \mathrm{mn}$ (b), at $500^{\circ} \mathrm{C}$ during $25 \mathrm{mn}(\mathrm{d})$ und at $460^{\circ} \mathrm{C}$ during $8 \mathrm{~h}(\mathrm{f})$.

mechanisms, one continuous for the temperatures of $600^{\circ} \mathrm{C}$ and $500^{\circ} \mathrm{C}$ where diffusion is carried out in volume and accomplished by twin formation. The other is of discontinuous type in the case of the temperature of $460^{\circ} \mathrm{C}$ with diffusion through the grain boundaries. In the other hand the dissolution process is relatively slow for 


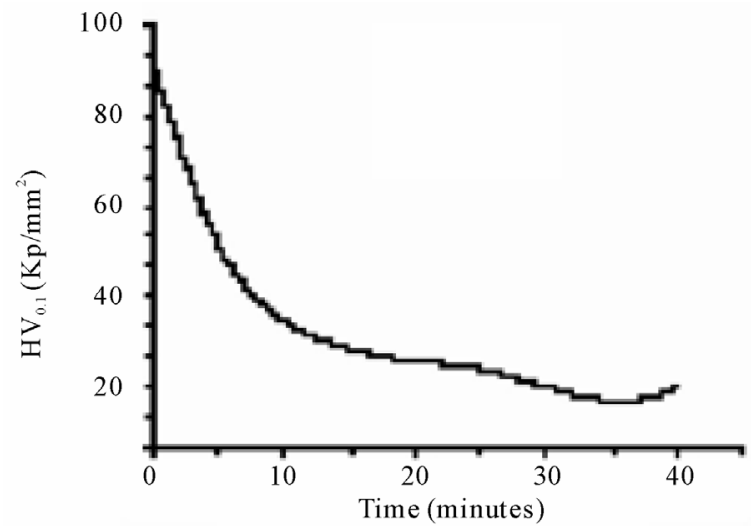

(a)

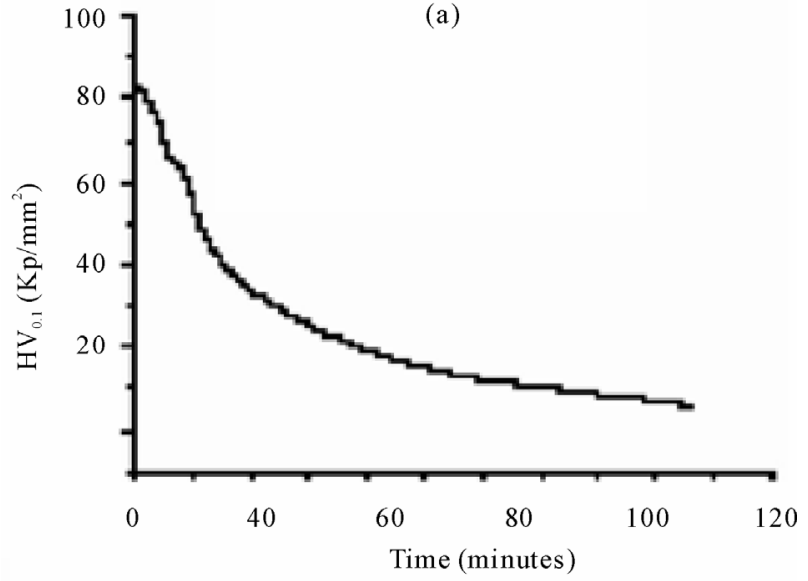

(b)

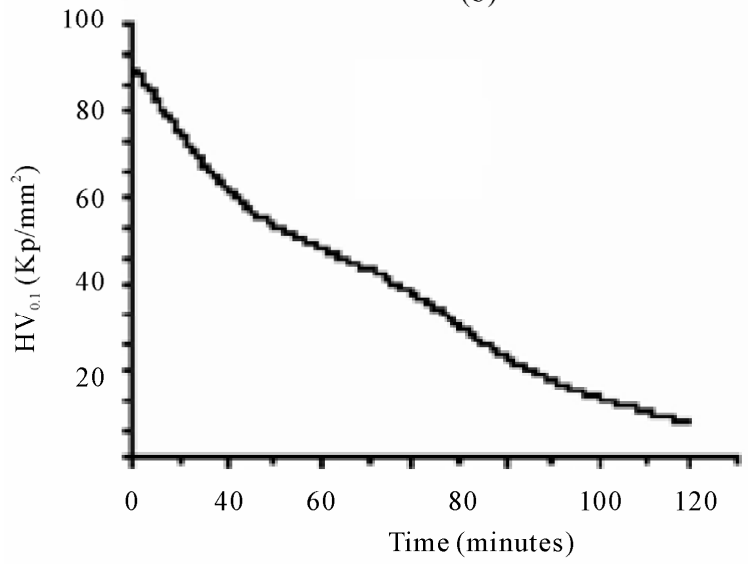

(c)

Figure 10. Hardness evolution $\mathrm{HV}_{0,1}$ during dissolution time of Cu-4.6 at\% In alloy, after homogenization during 27 days at $600^{\circ} \mathrm{C}$, quenched in water and annealing at $600^{\circ} \mathrm{C}$ (a), at $500^{\circ} \mathrm{C}\left(\right.$ b), and at $460^{\circ} \mathrm{C}$ (c).

the temperature of $460^{\circ} \mathrm{C}$, slow down probably by the spheroidisation of the lamellate precipitate.

\section{REFERENCES}

[1] Z. Boumerzoug, "Précipitation Discontinue dans les Alli- ages Binaires," Thèse de Magistère, Constantine, 1992.

[2] W. Gust, B. Prebel and I. Nguyen, "Untersuchung zur Diskontinuirlichen Auscheidung in Metallischen Systemen," Zeitschrift für Metallkunde, Vol. 4, No. 6, 1976, pp. 124-129.

[3] Y. C. Liu and H. I. Aaronson, "Fundamentals of Grain and Interphase Boundary Diffusion," Acta Metallurgica, No. 10, 1968, pp. 421-432.

[4] B. Prebel and W. Gust, "Cellular Precipitation in Supersaturated Solid Solutions," Journal of Materials Science, No. 3, 1975, pp. 754-755.

[5] Y. S. Kouchavenko, "The Mechanism of Phase Transformations in Crystalline Solids," Physics of Metals and Metallography, No. 5, 1975, pp. 289-294.

[6] R. A. Fournelle and J. B. Clark, "The Genesis of the Cellular Precipitation Reaction," Metallurgical and Materials Transaction, No. 3, 1972, pp. 312-318.

[7] H. Bohm, "precipitation Kinetics and Mechanism in $\mathrm{Cu}-7$ wt \% Ag Alloy," Zeitschrift für Metallkunde, Vol. 2, No. 3, 1959, pp. 544-549.

[8] Z. Boumerzoug and D. Hamana, "Cellular Precipitation from Phase Boundaries in Cu-9 wt\% Sb Alloy," Physics of Metals and Metallography, No. 7, 2001, pp. 345-348.

[9] K. N. Tu and D. Turnbull, "In Precipitation from solid solution," Acta Metallurgica, No. 6, 1972, pp. 121-124.

[10] Y. C. Liu and H. I. Aaronson, "The Cellular Reaction in PbSn Alloys," Acta Metallurgica, No. 3, 1976, pp. 167-171.

[11] J. B. Clark, "High Temperature, High Resolution Metallography," Gordon and Beach, New York, 1976, pp. 89-93.

[12] M. Frebel and J. Schenk, "Grain Growth and Control of Microstructure and Texture in Polycristalline Materials," Zeitschrift für Metallkunde, Vol. 4, No. 5, 1997, pp. 178182.

[13] B. Predel, M. Frebel and W. Gust, "Untersuchungen zur DP in Metallischen Systemen," West Deutscher Verlag, Opladen, 1997, pp. 98-101.

[14] C. W.Spenger and D. J. Mack, "Initiation and Growth of the Grain Boundary Discontinuous," Materials Transactions JIM , No. 5, 1981, pp. 53-54.

[15] B. Predel and W. Gust, "Macroscopic Kinetics of Discontinuous Precipitation in a Mg-8.5 wt\% Al Alloy," Materials Transactions JIM, No. 7, 1974, pp. 239-241.

[16] B. Predel and W. Gust, "Initiation Sites for Discontinuous Precipitation in Some Cu-Base Alloys," Journal of Materials Science, No. 6, 1972, pp. 211-214.

[17] P. Barrand, C. R.Tottle, D. Driver and A. B. Michelle, "Grain Boundary Relaxations in Iron-Chromium Alloys," Acta Metallurgica, Vol. 15, No. 9, 1967, pp. 1553-1555. doi:10.1016/0001-6160(67)90188-5

[18] M. Frebel and B. Prebel, "Beitrag Zur Kinetik der Diskon-Tinuierlichen Ausscheidung in Kupfer-IndiumMisch-Kristallen Mit 7.5 at\% Indium," Zeitschrift für Metallkunde, Vol. 3, No. 3, 1971, pp. 654-658. 
[19] H. Borchers, W. Scharfenberg and R. Zurstege, "Precipitation Behavior of $\alpha$-Solid Solutions of the Fe-Sn System," Acta Metallurgica, No. 8, 1968, pp. 405-408.

[20] W. Leo, "Microstructure and Internal Stresses in Cyclically Deformed Al and Cu Single Crystals," Zeitschrift für Metallkunde, Vol. 7, No. 3, 1967, pp. 456-458.

[21] B. Predel and M. Frebel, "Explanations of Third Element Effects upon the Growth Kinetics of Discontinuous Precipitation in Cu-In and Cu-Sb Alloys," Acta Metallurgica, No. 7, 1972, pp. 1259-1263. doi:10.1016/0001-6160(72)90056-9

[22] G. R. Speich, "Discontinuous Dissolution in Aged Alloys," Transactions AIME, Vol. 2, No. 4, 1963, pp. 227-231.

[23] M. Frebel, B. Predel and W. Klisa, "concentration Fluctuations and Thermodynamic Properties of Demixing Liquid Binary Alloys," Zeitschrift für Metallkunde, Vol. 6, No. 3, 1974, pp. 311-316.

[24] J. Petermann and E. Hornbogen, "Discontinuous Coarsening of Lamellar Cellular Precipitate in an Austenitic Fe-30 wt \% Ni-6 wt\% Ti alloy-I. Morphology," Zeitschrift für Metallkunde, Vol. 4, No. 5, 1968, p. 59, 814.

[25] C. W. Spenger and D. J. Mack, "Systematics of the Cellular Precipitation Reactions," Metallurgical and Materials Transactions, No. 7, 1972, pp. 84-87.

[26] C. W. Spenger and D. J. Mack, "Discontinuous Coarsening and Dissolution in an Fe 13.5 at\% Zn Solid Solution," Materials Transactions JIM, No. 3, 1972, pp. 254-258.

[27] D.Chethaum and N.Ridley, Materials Transactions JIM, No. 5, 1971, pp. 977-982.

[28] W. Gust, M. B. Hintz, B. Predel and U. Roll, "Diffusity of Impurities along Migrating and Stationary Grain," Acta
Metallurgica, Vol. 28, No. 9, 1980, pp. 1235-1244. doi:10.1016/0001-6160(80)90079-6

[29] W. Gust, B. Predel and U. Roll, "Impurity Diffusion of Al in Ni Single Crystals Studied by Secondary Ion Mass Spectrometry (SIMS)," Acta Metallurgica, Vol. 28, No. 10, 1980, pp. 1395-1398. doi:10.1016/0001-6160(80)90008-5

[30] H. I. Subakino, "The Discontinuous Precipitation Reaction in Dilute Al-Li Alloys," Metallography, No. 5, 1984, pp. 371-374.

[31] D. B. Williams and E. P. Buthler, Journal of Materials Science, No. 4, 1981, pp. 153-156.

[32] T. H. Chuang, W. Gust and R. A. Fournelle, "Review of Discontinuous Recipitation and Dissolution," Anais 7cbecimat, UFSC, Florianopolis, 1986, pp. 37-41.

[33] S. P. Gupta, "Initiation and Growth of the Grain Boundary Discontinuous Precipitation Reaction," Journal of Materials Science, No. 7, 1986, pp. 225-227.

[34] I. G. Solarzano and W. Gust, "Microstructural Characteristics of Splatquenched Aluminium-Copper Alloys," Materials Science Forum, 1992, pp. 659-664.

[35] J. M. Schapiro and J. S. Kirkaldy, "The Kinetics of Discontinuous Precipitation in Copper-Indium Alloys," Acta Metallurgica, No. 3, 1968, pp. 1239-1252.

[36] S. P. Gupta and B. Prassard, "Morphology and Chemical Nanoanalysis of Discontinuous Precipitation in $\mathrm{Mg} \mathrm{Al}$ Alloys-I. Regular Growth," Zeitschrift für Metallkunde, Vol. 3, No. 8, 1987, pp. 91-95.

[37] M. Hansen and K. Anderko, "Constitution of Alloys," McGraw-Hill, New York, 1958, pp. 278-281. 